\title{
PANORAMA REGIONAL DOS VIVEIROS MUNICIPAIS DO ESTADO DE GOIÁS
}

\author{
REGIONAL OVERVIEW OF MUNICIPAL NURSERIES IN THE GOIÁS STATE
}

Thales Augusto Ferreira Queiroz¹, Daniela Pereira Dias²

\section{RESUMO}

A demanda por mudas florestais para arborização de ruas e paisagismo, criação de áreas verdes, regularização ambiental, recuperação de áreas degradadas (RAD) pode ser suprida pelos viveiros municipais. O objetivo desta pesquisa foi identificar os viveiros municipais do estado de Goiás e apresentar um panorama sobre sua distribuição e caracterização regional. Os dados foram obtidos por meio de consulta eletrônica, que também buscou conhecer: número de habitantes dos municípios, região de planejamento, tipologia vegetal e instituições de ensino e pesquisa com cursos associados à produção de mudas. Também foi consultado se os viveiros possuem cadastro no Registro Nacional de Produtores de Sementes e Mudas. Os resultados indicaram que 23,6\% dos municípios de Goiás possuem viveiros municipais. A informação sobre ausência ou presença destes viveiros não foi encontrada somente em 14 dos 246 municípios existentes. De maneira geral, os municípios com maior número habitantes e localização central apresentam viveiros. As formações florestais variaram de acordo com a região de planejamento do estado. Nenhum dos viveiros municipais possui registro. Foram listadas 37 instituições para possíveis parcerias com viveiros. A ausência destes compromete a arborização urbana, RAD e regularização ambiental. As parcerias podem incentivar politicas públicas de produção de mudas em Goiás.

Palavras-chave: Educação ambiental; Produção florestal; Qualidade ambiental; Regularização ambiental; Restauração ecológica.

\begin{abstract}
Demand for forest seedlings used for urban forestry and landscaping, creation of green areas, environmental regularization, recovery of degraded areas (RDA) may be met by municipal nurseries. The objective of this study was to identify the municipal nurseries in the state of Goiás and to present an overview of its distribution and regional characterization. The data were monitored through electronic consultation, with also sought to know: number of inhabitants of the municipalities, planning region, vegetation type and teaching and research institutions that have courses associated with the production of seedlings. It was also consulted if municipal nurseries have the National Registry of Seed and Seedling Producers (RENASEM). The results indicated that $32.00 \%$ of the municipalities have municipal nurseries. Information on the absence or presence of these nurseries was not found only in 21 of the 246 existing municipalities. In general, the municipalities with the largest number of inhabitants and central location have nurseries. The vegetation formations varied according to the state's planning region. None of the municipalities is registered with RENASEM. A total of 37 institutions were listed for possible partnerships with nurseries. Their absence compromises urban forestry, RDA and environmental regularization. The partnerships can encourage public policies for seedling production in Goiás.
\end{abstract}

Keywords: Environmental education; Forest Production; Environmental quality; Environmental regularization; Ecological restoration.

Recebido em 18.05.2020 e aceito em 03.12.2020

1 Engenheiro Florestal. Analista Ambiental da Secretaria de Meio Ambiente e Desenvolvimento Sustentável da Prefeitura Municipal de Mineiros. Mineiros/GO. Email: tafq@hotmail.com

2 Engenheira Florestal. Profa. Dra. Universidade Federal de Jataí. Jataí/GO. Email: danieladias@ufg.br 


\section{INTRODUÇÃO}

O crescimento da população urbana muitas vezes não tem ocorrido associado com o desenvolvimento socioeconômico. No Brasil, a porcentagem da população urbana alcançou 83\% (ANGEOLETTO et al., 2016). Com o desenvolvimento das cidades, é cada vez maior a preocupação quanto à manutenção da qualidade de vida nesses centros urbanos (DA SILVA et al., 2019). Inclusive a exigência de "tornar as cidades e assentamentos humanos inclusivos, seguros, resilientes e sustentáveis" foi trazida no 11ㅇo objetivo para desenvolvimento sustentável da Organização das Nações Unidas.

Nas cidades com crescente aumento da população urbana ocorre uso excessivo do solo, incremento da impermeabilização, além da poluição industrial e do escapamento dos carros nas áreas de metrópoles, gerando alterações no ambiente e formação, nestes locais, de um clima típico, caracterizado pelas altas temperaturas e baixa umidade relativa do ar, sendo estes elementos atenuados pelo processo de arborização (SOUZA et al., 2017). Assim, a arborização urbana tem se tornado importante no que se refere à qualidade de vida para o cidadão e sobre os problemas das cidades (MARTELLI, 2016). Essa vegetação quando bem planejada e estruturada traz inúmeros benefícios como o controle da poluição do ar, conforto ambiental com redução da temperatura, abrigo à fauna, equilíbrio da umidade no ar, convívio social, recreação e a prática de atividades físicas, favorecendo a melhoria da qualidade de vida (MARTELLI, 2016). Porém, tem sido considerado um grande desafio para os administradores municipais o planejamento e a manutenção dessa vegetação, que convive diretamente sob influência antrópica.

North et al. (2015) mencionaram que escolhas inadequadas para a realização do plantio fazem com que muitas árvores sejam removidas a cada ano, devido aos seus impactos negativos sobre a infraestrutura urbana antes que seus benefícios sejam plenamente realizados. Viveiros com infraestruturas adequadas, profissionais capacitados e conhecimentos técnicos sobre os tratos culturais das espécies produzidas, impactam diretamente na quantidade e qualidade das mudas. Assim, tecnologias e protocolos específicos envolvendo a germinação e produção de mudas para espécies nativas do local onde o viveiro está localizado podem reduzir o replantio e a perda da diversidade.

Os viveiros, vinculados às prefeituras municipais, tem papel importante na arborização das cidades (GONÇALVES et al., 2004), além de elaborar e executar programas de educação ambiental, fomento com produtores rurais ou para doações de forma direta à associações, cooperativas ou ONG's e demais ações ambientais. A ausência de viveiros municipais sugere que a arborização das ruas de um município possa estar sendo prejudicada (GONÇALVES et al., 2004) e que as demandas para recuperação de áreas degradadas não são atendidas 
(MARTINS et al., 2014), bem como as associadas à regularização ambiental. Assim, o conhecimento da infraestrutura dos viveiros responsáveis pela produção de mudas é essencial para que seja possível planejar e direcionar políticas públicas para promover a regularização ambiental (IPEA, 2015) e criar um ambiente urbano favorável.

A caracterização dos viveiros tem sido considerada uma tarefa importante por vários autores (GONÇALVES et al., 2004; MESQUITA et al., 2011; FREITAS et al., 2013; MARTINS et al., 2014). As demandas para recuperação de áreas degradadas poderão ser levantadas a partir da avaliação dos viveiros, sobretudo no que se refere à sua capacidade de fornecimento de mudas, procedência das sementes e mudas, diversidade de espécies produzidas, quantificação de nativas e exóticas e do ecossistema de origem da espécie, além das dificuldades técnicas que envolvem o processo produtivo (MARTINS et al., 2014). Segundo Mesquita et al. (2011), a diversidade de espécies florestais produzidas nos viveiros pode indicar a (in)suficiência do número de espécies que representam as diferentes formações vegetais de um Estado. Além disso, o levantamento de dados sobre os viveiros pode sinalizar quais são as demandas potenciais e indicar a importância dos viveiros para a comunidade onde o mesmo está inserido, seja esta importância social, econômica e/ou ambiental (FREITAS et al., 2013).

A atual situação dos viveiros e quantificação das mudas produzidas encontra-se pouco estruturada ou inexistente em diversas regiões do país (FREITAS et al., 2013; IPEA, 2015). Especificamente no estado de Goiás, poucos dados foram levantados sobre o tema e raros trabalhos são encontrados na literatura (SANTOS; QUEIROZ, 2011; IPEA, 2015), onde são apresentadas condições pontuais com a participação de poucos municípios. Considerando que Goiás possui uma área de $340.110,39 \mathrm{~km}^{2}$ e apenas $17,05 \mathrm{~km}^{2}$ destinados à área de viveiros de mudas (IBGE, 2010), a importância dos viveiros florestais na economia (VASCONCELOS et al., 2012) e a crescente demanda por mudas após o novo código florestal brasileiro e outras normativas para adequação ambiental das propriedades rurais, estudos que visam identificar e caracterizar a situação atual de viveiros em Goiás se fazem necessários.

O objetivo deste estudo foi identificar os viveiros municipais do estado de Goiás e apresentar um panorama sobre sua distribuição e caracterização regional, em busca de conhecer as regiões que possuem déficit de viveiros municipais, analisar aspectos da localização, os remanescentes de vegetação natural e indicar sugestões de parcerias entre municípios e entidades de ensino e pesquisa que possuem cursos associados à produção de mudas.

\section{MATERIAL E MÉTODOS}


O Estado de Goiás, sétimo maior estado do país como $340.203,329 \mathrm{~km}^{2}$, possui população estimada para 2020 de 7.113 .540 habitantes e índice de desenvolvimento humano (IDH) de 0,735 (IBGE, 2010), sendo considerado o oitavo IDH do Brasil. Os biomas encontrados em território goiano são o Cerrado e fragmentos de Mata Atlântica. De acordo com o diagnóstico da produção de mudas florestais nativas, divulgado em 2015 pelo Instituto de Pesquisa Econômica Aplicada (IPEA), a capacidade máxima de produção de sementes e mudas de Goiás é de 1 - 1,5 milhões por ano, o mesmo valor apresentado para o número de mudas de espécies nativas produzidas anualmente.

A coleta de informações sobre os viveiros municipais produtores de mudas do estado de Goiás ocorreu em junho de 2020, a partir da consulta em sites da internet. Em busca de identificar a ausência ou presença do viveiro municipal nos 246 municípios de Goiás, a consulta foi realizada no Google, com as palavras-chave: "nome do município", "GO", "viveiro", "mudas" e "municipal". Para a identificação dos municípios que detinham viveiro, foram analisados os sites das prefeituras municipais, das câmaras municipais, reportagens em sites ou jornais, planos de governos de candidatos à cargos públicos nas prefeituras, páginas do facebook, entre outros. Por outro lado, consideramos que o município não possuía viveiro municipal quando as informações encontradas sugeriam a inexistência do mesmo e, ainda, quando a criação do viveiro fazia parte do plano diretor ou projetos de candidatos a cargos públicos. Além disso, em alguns municípios não foram encontradas referências ou informações. Estes dados, após sua coleta, foram organizados e armazenados em formato de planilha do Microsoft Excel.

O registro da ocorrência de viveiros foi relacionado com variáveis de caracterização dos municípios como área, número de habitantes e região em que se encontram, tendo como base os dados do Instituto Brasileiro de Geografia e Estatística (IBGE, 2010). O Produto Interno Bruto (PIB) dos municípios goianos também foi obtido (IBGE, 2010). Além disso, a tipologia vegetal predominante no município descrita por Sano et al. (2006) também foi consultada, assim como a área ocupada por uso agrícola e vulnerabilidade à erosão dos municípios. A taxa de desmatamento dos municípios estudados, com dados de 2002 a 2008, foi obtida no Relatório Técnico de Monitoramento do Desmatamento no Bioma Cerrado, emitido pelo Instituto Brasileiro do Meio Ambiente e dos Recursos Naturais Renováveis (Brasil, 2009).

Com o objetivo de motivar parceiras com os viveiros municipais, as instituições de ensino e pesquisa, públicas e particulares, do estado de Goiás foram identificadas no site do Ministério da Educação (MEC). A partir disso, os sites das instituições foram consultados no intuito de identificar os cursos de graduação associados com produção de mudas e sua localização no estado de Goiás. Por fim, fez-se a consulta no Registro Nacional de Produtores de Sementes e Mudas (RENASEM) do Ministério da Agricultura, Pecuária e Abastecimento 
(MAPA), para averiguar o cadastro destes viveiros, exigência conforme o Art. 8ㅇ da Lei № 10.711/03, que dispõe sobre o Sistema Nacional de Sementes e Mudas.

\section{RESULTADOS E DISCUSSÃO}

Dos 246 municípios goianos, em 232 foram encontradas informações sobre o viveiro municipal, o que representa $94,31 \%$ dos municípios e $93,58 \%$ da área total do estado. Não foi possível encontrar informações em 14 municípios. Em estudos realizados por meio de questionários, Winters et al. (1992) e Gonçalves et al. (2004) obtiveram resposta de 51,60\% (no estado de São Paulo, em 1991) e de 31,70\% (em Minas Gerais, em 2003) dos municípios.

Do total, 58 municípios dispunham de viveiros para produção de mudas (Figura 1) representando $23,58 \%$ dos municípios goianos, ocupando mais de $30,00 \%$ do espaço territorial de Goiás.

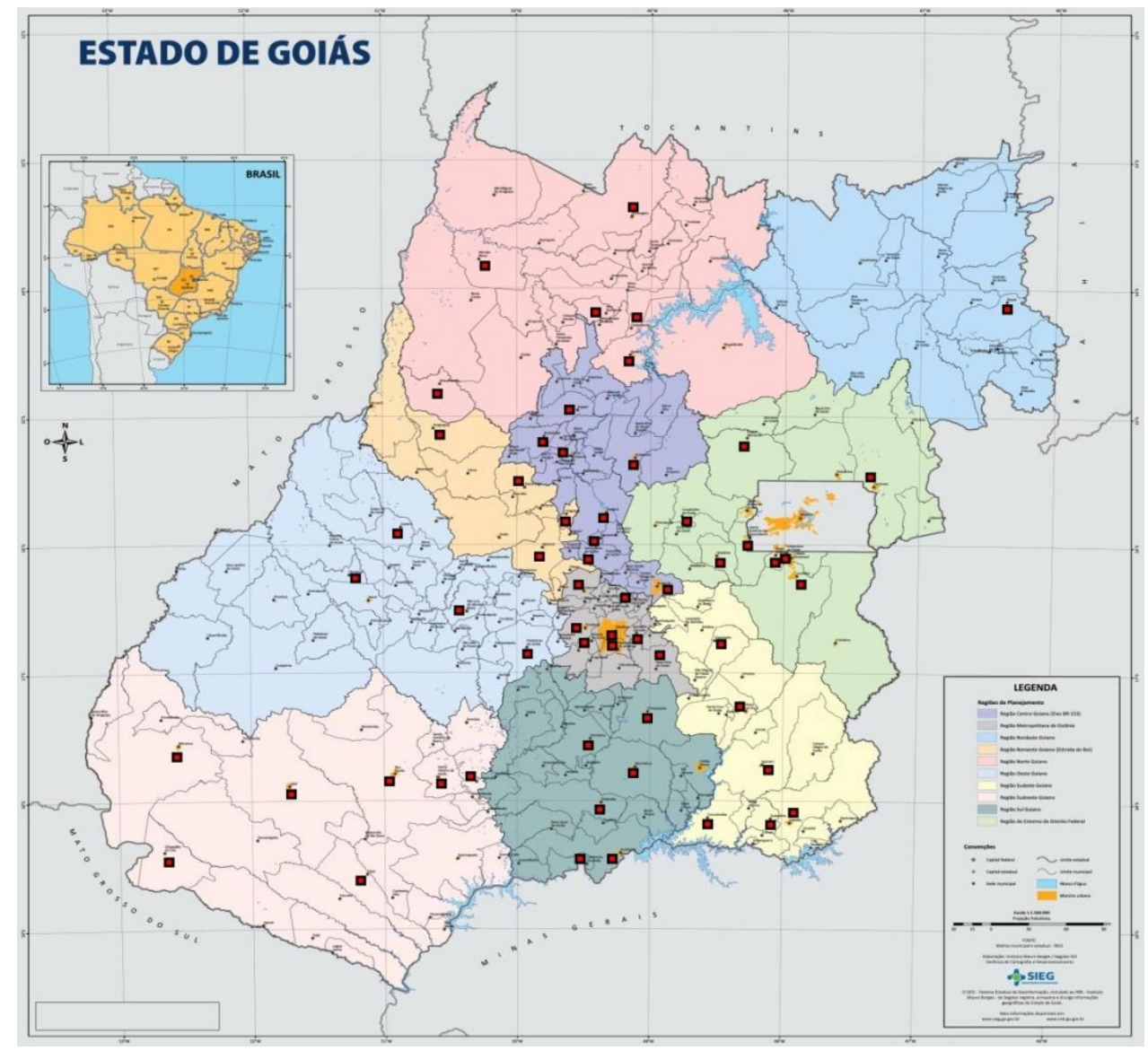

Fonte: Modificado de SIEG (2020)

Figura 1. Viveiros de plantas municipais em Goiás (•) após levantamento realizado em 2020. Figure 1. Municipal plants nurseries in Goiás ( $\mathbf{m})$ after a survey carried out in 2020.

No levantamento dos viveiros municipais realizado em São Paulo, entre os munícipios que participaram do diagnóstico de Winters et al. (1992), 34,57\% possuíam viveiros, enquanto 
que em Minas Gerais, Gonçalves et al. (2004) relataram que 46,47\% dos municípios que participaram da pesquisa apresentaram esta estrutura.

Os municípios em que não encontramos informações sobre viveiros (14) possuem pequeno porte (de 1597 a 53300 habitantes) e área variando de 84,63 a $6160,70 \mathrm{~km}^{2}$. Isso demostra que a produção de mudas poderia ser aumentada e, consequentemente, mais arborizadas poderiam ser as cidades, mais áreas de preservação permanente (APPs) e de reserva legal $(R L)$ poderiam estar regularizadas. A ampliação dos pontos de distribuição de mudas (ampliação do número de viveiros) geralmente é apoiada pela população, pois além dos benefícios da arborização urbana, esta promove o resgate da identidade e da autoestima da cidade (SILVA; MORAES, 2016).

Quanto maior o número de habitantes dos municípios maior a presença de viveiros municipais para produção de mudas (Figura 2).

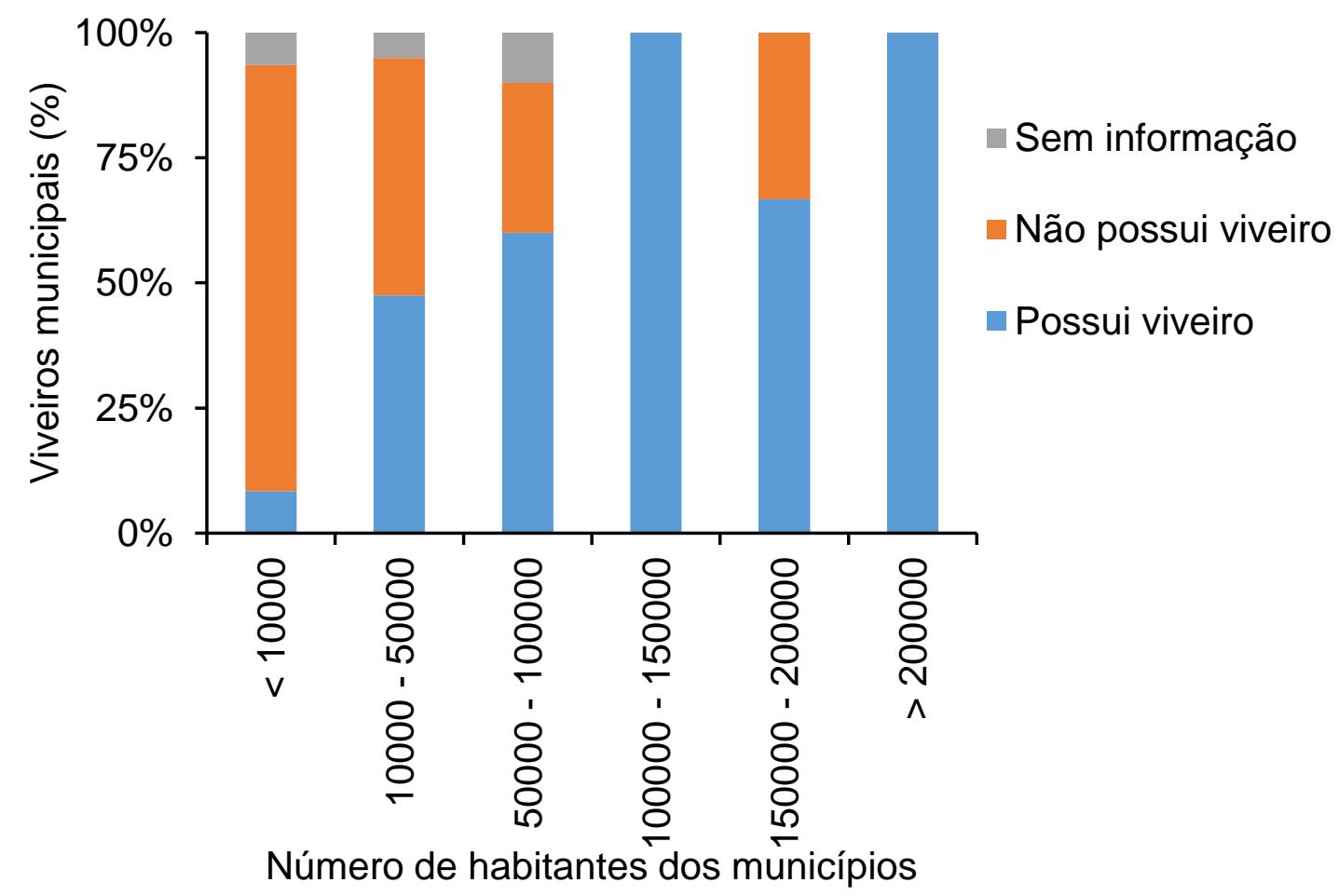

Figura 2: Quantificação da presença e ausência de viveiros municipais em classes de número de habitantes dos municípios do estado de Goiás, assim como aqueles em que não foram obtidas informações.

Figure 2. Quantification of the presence and absence of municipal nurseries by the number of inhabitant's classes in the municipalities of Goiás state, as well as those in which information was not obtained.

A maioria dos municípios goianos (155) possui menos de 10000 habitantes, onde destes apenas $8,39 \%$ dos municípios possuem viveiros. Nos municípios que apresentam população entre 10000 e 50000 habitantes (69), 47,46\% possuem viveiros municipais, enquanto nos que 
possuem entre 50000 e 100000 habitantes (10 municípios), 60,00\% possuem viveiro municipal. Por outro lado, somente 12 municípios apresentam mais de 100000 habitantes em Goiás, e deste grupo, apenas em Água Lindas de Goiás (150000 a 200000 habitantes) não foi encontrada informações sobre o viveiro municipal, o que nos permitiu inferir que o município não possui viveiro. Em seu plano diretor participativo, em sua proposta preliminar, de 2016, previa a criação de Parques Ecológicos e o Viveiro Municipal. Assim, municípios de maior porte apresentam a arborização urbana, de modo geral, mais bem estruturada quando comparadas às de menor porte. Os habitantes das pequenas cidades possuem pouco conhecimento referente aos benefícios da arborização urbana, atrelado a isso, na maioria das vezes, estas cidades não possuem um correto projeto de arborização (SANTOS et al., 2018). Nas cidades, muitas vezes, a arborização tem função apenas ornamental, sem uma aplicabilidade ambiental.

O conhecimento da ocorrência ou não de um determinado tipo de vegetação para onde as mudas serão destinadas é importante para evitar a queda da biodiversidade de espécies da região, produzindo assim um maior número de espécies nativas. Por exemplo, no estudo realizado por Alonso et al. (2014), a diversidade total de espécies florestais da Mata Atlântica produzidas nos viveiros do Estado do Rio de Janeiro foi considerada baixa, assim como a diversidade média, já que mais da metade dos viveiros trabalhava com uma listagem de 50 ou menos espécies, número insuficiente considerando a diversidade de espécies florestais presentes nas diferentes formações vegetais do estado. Contudo, conhecer as fitofisionomias que ocorrem nos municípios se torna essencial para a produção das mudas no viveiro municipal. Pois, de acordo com Mesquita et al. (2011), a diversidade de espécies florestais produzidas nos viveiros pode indicar a (in)suficiência do número de espécies que representam as diferentes formações vegetais de um Estado.

De acordo com Sano et al. (2006), suscintamente há quatro tipos de vegetação natural em Goiás, sendo elas, savana presente em $89,84 \%$ dos municípios, seguido de floresta estacional semidecidual aluvial (34,15\%), floresta estacional decidual montana $(16,67 \%)$ e formações pioneiras fluviais e/ou lacustres (1,22\%). A tipologia savana e a floresta semidecidual são as formações florestais que apresentam mais distribuídas pelo estado, sendo também as predominantes em todas as regiões do estado, enquanto que as florestas deciduais estão presentes em sete regiões. As formações pioneiras foram encontradas em apenas duas regiões do estado, distribuídas em três municípios e apenas um deles possui viveiro municipal (Jussara).

Assim, a partir do referido estudo de Sano, na Tabela 1 apresentamos a porcentagem de ocorrência de Savana, Floresta estacional semidecidual aluvial, Floresta estacional decidual montana e Formações pioneiras fluviais e/ou lacustres das 10 regiões de planejamento de Goiás. 
Tabela 1. Porcentagem de municípios com os diferentes remanescentes de vegetação natural nas regiões de planejamento de Goiás, porcentagem de municípios com viveiros municipais que possuem as formações florestais descritas, municípios das regiões de planejamento que possuem viveiros (\%), área dos municípios que possuem viveiro por região de planejamento (\%) e a densidade (número de viveiros por $10.000 \mathrm{~km}^{2}$ ) em cada região.

Table 1. Percentage of municipalities with different remnants of natural vegetation in the planning regions of Goiás, percentage of municipalities with municipal nurseries that have the described forest formations, municipalities in the planning regions that have nurseries (\%), area of the municipalities that have a nursery by planning region (\%) and density (number of nurseries per $10,000 \mathrm{~km}^{2}$ ) in each region.

\begin{tabular}{lccccccc}
\hline Região de Goiás & S & FS & FD & FP & Municípios & Área & Densidade \\
\hline Norte Goiano & 15,38 & 20,00 & & & 23,07 & 20,85 & 1,01 \\
Sudoeste Goiano & 26,92 & 66,67 & 100,00 & 26,92 & 51,65 & 1,16 \\
Sul Goiano & 32,00 & 45,45 & 0,00 & 23,07 & 48,31 & 2,39 \\
Noroeste Goiano & 50,00 & 50,00 & 33,33 & 30,77 & 33,34 & 2,57 \\
Sudeste Goiano & 40,91 & 40,00 & & & 22,73 & 50,22 & 1,99 \\
Entorno do Distrito Federal & 40,91 & 50,00 & & 42,11 & 46,54 & 2,23 \\
Nordeste Goiano & 0,00 & 0,00 & 0,00 & 5,00 & 5,46 & 0,28 \\
Centro Goiano & 29,17 & 62,50 & 50,00 & & 25,81 & 35,50 & 4,33 \\
Metropolitana de Goiânia & 46,15 & 40,00 & 50,00 & & 40,00 & 57,14 & 10,81 \\
Oeste Goiano & 21,05 & 25,00 & 22,22 & 100,00 & 9,30 & 12,55 & 0,70 \\
\hline
\end{tabular}

Nota: $\mathrm{S}$ = Savana; FS = Floresta estacional semidecidual aluvial; FD = Floresta estacional decidual montana; FP = Formação pioneira fluviais e/ou lacustres.

A porcentagem de municípios que possuem viveiros por região de planejamento variou de 5,00 a 42,11\%, respectivamente, no Nordeste Goiano e Entorno do Distrito Federal (Tabela 1). Mesmo a Região Metropolitana de Goiânia e o Centro Goiano tendo apresentando o mesmo número de viveiros municipais que a do Entorno do Distrito Federal (um total de oito viveiros), a porcentagem do Entorno foi superior devido ao menor número total de munícipios desta região de planejamento. Tais regiões são consideradas as mais desenvolvidas do estado (IBGE, 2010). Isto pode justificar parcialmente o maior número de viveiros, somado à densidade demográfica, à história do município, bem como a atenção dada às questões ambientais e recursos financeiros públicos disponíveis. Além disso, os 10 municípios que concentram aproximadamente $60,00 \%$ do PIB goiano (Goiânia, Anápolis, Aparecida de Goiânia, Rio Verde, Catalão, Senador Canedo, Itumbiara, Jataí, Luziânia e São Simão), segundo o IBGE (2010), possuíam viveiro municipal, sendo três deles pertencentes à Região metropolitana de Goiânia. Por outro lado, o Nordeste Goiano e o Oeste Goiano apresentaram as menores porcentagens de municípios com viveiros (5,00 e $9,30 \%$, respectivamente).

Dentre as regiões de planejamento de Goiás, cinco se destacaram quanto à porcentagem de área dos municípios que possuem viveiro, com valores entre 46 e 57\% (Tabela 1). De acordo com Duarte et al. (2018), algumas poucas cidades se destacam pela arborização 
urbana bem planejada, enquanto a maior parte das cidades brasileiras nem sequer possuem leis específicas ou corpo técnico especializado para o planejamento, execução e fiscalização da arborização urbana. E a presença de viveiros municipais tem relação direta com estas questões.

A densidade de viveiros municipais por $10.000 \mathrm{~km}^{2}$ variou entre as regiões de planejamento goianas (Tabela 1). As regiões que apresentaram menor densidade foram a Nordeste $(0,28)$, seguida da Oeste $(0,70)$. As demais regiões de planejamento mostraram densidade de viveiros por $10000 \mathrm{~km}^{2}$ superior a 1,00, com destaque para a Metropolitana de Goiânia, com 10,81. Este fator está relacionado com a distância entre viveiros municipais, pois, uma maior densidade de viveiros mostra maior aproximação entre eles, facilitando assim parcerias entre os viveiros já existentes, como troca de sementes ou mudas de espécies de maior ocorrência em determinada região. Já uma menor densidade, subtende-se que possua uma maior distância entre os viveiros municipais, sendo recomendadas assim parcerias entre os municípios que possuem viveiro municipal e os que não possuem. Considerando a deficiência de viveiros por área, a escolha de áreas prioritárias para implantação de viveiros municipais poderia levar em conta as formações vegetacionais naturais remanescentes encontradas nas regiões de planejamento (conforme Tabela 1). Tal escolha poderia partir do governo estadual ou dos próprios municípios (isolados ou em grupo), e poderia contar inclusive com a participação e incentivo de empresas privadas e a população.

Ao pesquisar no banco de dados do Ministério da Agricultura e Abastecimento (MAPA), observou-se que nenhum dos viveiros municipais do estado de Goiás possui registro no RENASEM. Tal registro é obrigatório, mesmo que seja produção de mudas para doação, porém tem sido dispensado quando as mudas produzidas possuem destino de uso próprio, como ocorre para os viveiros municipais. Ainda cabe ressaltar a necessidade dos viveiros registrados possuírem um Responsável Técnico (RT) pela produção (Engenheiro Florestal ou Agrônomo), segundo Walker et al. (2011). Gonçalves et al. (2004), analisando a qualidade das mudas em viveiros públicos e privados, encontraram deficiência de mudas voltadas a arborização urbana em ambos tipos de viveiros, fatores estes devem-se, em muitos casos, à ausência de um RT para coordenar a produção. Além da qualidade das mudas às quais o RT é responsável, é importante também analisar as espécies produzidas, visto que, a presença significativa de espécies inadequadas por possuírem princípios tóxicos, alérgicos, espinhos ou grande potencial invasor podem trazer prejuízos à saúde da população e prejudicar a biodiversidade local (BIONDI; LEAL, 2008).

$\mathrm{Na}$ Tabela 2, foram listadas as 37 instituições de ensino e pesquisa localizadas no Estado de Goiás com sua respectiva localização (região de planejamento e município), com os cursos voltados à produção de mudas e meio ambiente e o tipo (pública ou privada). 
Tabela 2. Instituições de ensino e pesquisa localizadas no Estado de Goiás com sua respectiva localização (região de planejamento e município), cursos voltados à produção de mudas e meio ambiente e tipo (pública ou privada)

Table 2. Teaching and research institutions located in the State of Goiás with their respective location (planning region and municipality), courses focused on seedling production and the environment and type (public or private)

\begin{tabular}{|c|c|c|c|c|}
\hline Instituição* & Região* & Município & Cursos & Tipo*** \\
\hline UFCAT & SEG & Catalão & $\begin{array}{l}\text { Ciências Biológicas } \\
\text { Agronomia, Ciências Ambientais, Ciências Biológicas, Ecologia }\end{array}$ & PU \\
\hline UFG & MG & Goiânia & $\begin{array}{l}\text { e Analise Ambiental, Eng. Ambiental e Sanitária e Eng. } \\
\text { Florestal. }\end{array}$ & PU \\
\hline UFJ & SOG & Jataí & Agronomia, Ciências Biológicas e Eng. Florestal. & PU \\
\hline IFG & E-DF & Formosa & Ciências Biológicas & PU \\
\hline IFG & MG & Goiânia & Eng. Ambiental e Saneamento Ambiental & PU \\
\hline UEG & CG & Anápolis & Ciências Biológicas & PU \\
\hline UEG & SEG & Ipameri & Agronomia e Eng. Florestal & PU \\
\hline UEG & OG & Iporá & Ciências Biológicas & PU \\
\hline UEG & NOG & Itapuranga & Ciências Biológicas & PU \\
\hline UEG & SG & Morrinhos & Ciências Biológicas & PU \\
\hline UEG & OG & Palmeiras de Goiás & Agronomia e Ciências Biológicas & PU \\
\hline UEG & NG & Porangatu & Ciências Biológicas & PU \\
\hline UEG & SOG & Quirinópolis & Ciências Biológicas & PU \\
\hline IFGoiano & CG & Ceres & Agronomia e Técnico em Meio Ambiente & PU \\
\hline IFGoiano & MG & Hidrolândia & Técnico em Meio Ambiente & PU \\
\hline IFGoiano & OG & Iporá & Agronomia & PU \\
\hline IFGoiano & SG & Morrinhos & Agronomia & PU \\
\hline IFGoiano & SOG & Rio Verde & Agronomia & PU \\
\hline IFGoiano & SEG & Urutaí & Agronomia & PU \\
\hline PUCGO & MG & Goiânia & Biologia, Eng. Ambiental e Técnico Ambiental & PA \\
\hline Uni-Goiás & MG & Goiânia & Agronomia e Ciências Biológicas & PA \\
\hline UniAraguaia & MG & Goiânia & Ciências Biológicas, Eng. Agronômica e Ambiental & PA \\
\hline Fac. Delta & MG & Goiânia & Tecnologia em Gestão Ambiental & PA \\
\hline Fac. Senac & MG & Goiânia & Gestão Ambiental & PA \\
\hline UniEVANGÉLICA & CG & Anápolis & Agronomia e Ciências Biológicas & PA \\
\hline FAMA & CG & Anápolis & Agronomia, Ciências Biológicas e Eng. Ambiental e Sanitária & PA \\
\hline UniCaldas & SG & Caldas Novas & Ciências Biológicas e Eng. Ambiental & PA \\
\hline FAl & OG & Iporá & Gestão Ambiental e Eng. Ambiental e Sanitária & PA \\
\hline UNIFASC & SG & Itumbiara & Agronomia & PA \\
\hline UNIFIMES & SOG & Mineiros & Agronomia, Eng. Ambiental e Sanitária e Florestal & PA \\
\hline UNIDESC & E-DF & Luziânia & Agronomia & PA \\
\hline FAQUI & SOG & Quirinópolis & Agronomia & PA \\
\hline UniRV & SOG & Rio Verde & Agronomia, Ciências Biológicas e Eng. Ambiental & PA \\
\hline UniRV & OG & Caiapônia & Eng. Ambiental & PA \\
\hline UniBRÁS & SOG & Rio Verde & Agronomia & PA \\
\hline UniMB & $O G$ & São Luiz M. Belos & Ciências Biológicas, Agronomia & PA \\
\hline GOYAZES & MG & Trindade & Ciências Biológicas & PA \\
\hline
\end{tabular}

Instituição: UFCAT = Universidade Federal de Catalão; UFG = Universidade Federal de Goiás; UFJ = Universidade Federal de Jataí; IFG = Instituto Federal de Goiás; UEG = Universidade Estadual de Goiás; IFGoiano = Instituto Federal Goiano; PUCGO = Universidade Católica de Goiás; Uni-Goiás = Centro Universitário de Goiás; UniAraguaia = UniAraguaia Centro Universitário; Fac. Delta $=$ Faculdade Delta; Fac. Senac = Faculdade de Tecnologia, Senac; UniEVANGÉLICA = Centro Universitário de Anápolis; FAMA = Faculdade Metropolitana de Anápolis; UniCaldas = Faculdade de Caldas Novas; FAI = Faculdade de Iporá; UNIFASC = Faculdade Santa Rita de Cássia; UNIFIMES = Centro Universitário de Mineiros; UNIDESC = Centro Universitário de Desenvolvimento do Centro Oeste; FAQUI = Faculdade Quirinópolis; UniRV = Universidade de Rio Verde; UniBRÁS = Faculdade Objetivo de Rio Verde; UniMB = Centro Universitário Montes Belos; GOYAZES = Centro Educacional União de Goyazes.

${ }^{* *}$ Região: NG = Norte Goiano; SOG = Sudoeste Goiano; SG = Sul Goiano; NOG = Noroeste Goiano; SEG = Sudeste Goiano; E-DF = Entorno do Distrito Federal; NEG = Nordeste Goiano; $C G$ = Centro Goiano; MG = Metropolitana de Goiânia; OG = Oeste Goiano. ***Tipo: PU = Pública; PA = Particular

As parcerias dos viveiros municipais com as instituições de ensino e pesquisa do estado, públicas ou privadas, podem ocorrer desde que estas possuam cursos de graduação relacionados com produção de mudas e meio ambiente. As parcerias voltadas à produção de mudas, tanto em pesquisas quanto fomentando a produção, devem se incentivadas, minimizando os custos de produção e de implantação dos viveiros, além de facilitar projetos 
ambientais nos municípios. O RT pode facilitar parcerias entre universidades e os viveiros municipais. O conhecimento do responsável pelo viveiro referente à produção das mudas e coordenação de pessoal pode auxiliar o desenvolvimento da experimentação, como por exemplo, programas de melhoramento, testes de germinação dentre outros, aumentando assim o ganho científico de determinadas regiões acrescido da conservação ambiental. Existem iniciativas, como a descrita por Ramos et al. (2012), em que as instituições de ensino realizam projetos ligados à educação ambiental a partir da construção de um viveiro educativo, onde os discentes relacionam todos os componentes curriculares de forma interdisciplinar.

A responsabilidade pela implantação e manejo da arborização urbana das prefeituras municipais independe do porte do município. Por isso, o planejamento da arborização urbana pode facilitar a implantação e reduzir os custos, caso contrário, a arborização passa a ter um caráter de remediação, à medida que tenta se encaixar dentro das condições já existentes (PIVETTA; SILVA FILHO, 2002). Para uma arborização mais organizada, devem ser elaboradas normas de arborização, com parcerias públicas e/ou privadas, com a participação da comunidade, que também cuida da arborização.

No contexto municipal ou regional, os aspectos ambientais do plantio de mudas tanto nas cidades quanto na zona rural apresentam influência direta e indireta sobre a sociedade com a reposição de áreas desmatadas, melhorando a qualidade de vida, geração de renda e diminuição de pressão nas florestas nativas (FREITAS et al., 2013). Para isso, especificamente no meio urbano, é necessário um planejamento específico para retirar e introduzir espécies vegetais, tendo em vista a necessidade de atenção quanto ao plantio, que deve levar em conta critérios como espaçamento, coveamento, área livre de pavimento, tutoramento e grades de proteção, além de manejo adequado realizado por pessoal qualificado, garantindo que a arborização desempenhe a função de melhoria da qualidade de vida dos munícipes (DA SILVA et al., 2019). De acordo com o IBGE, (2010), o Brasil possui $84,40 \%$ da sua população vivendo em áreas urbanas e $15,60 \%$ na zona rural. Já o centro-oeste brasileiro possui $88,80 \%$ da população em centros urbanos e 11,20\%, em rurais. O estado de Goiás por sua vez possui $90,30 \%$ da sua população em áreas urbanas e 9,70\% em áreas rurais. Um programa de arborização urbana em todo o estado beneficiaria mais de seis milhões de goianos. Essa vegetação quando bem planejada e estruturada favorece inúmeros benefícios como controle da poluição do ar, conforto ambiental com redução da temperatura, abrigo à fauna, equilíbrio da umidade no ar, convívio social, recreação e a prática de atividades físicas favorecendo a melhoria da qualidade de vida (MARTELLI, 2016).

Dessa forma, a educação ambiental é imprescindível para a conscientização da população sobre a importância da arborização urbana e a conservação dos ambientes naturais. Por exemplo, ocorrem muitas perdas de mudas utilizadas na implantação da arborização de ruas 
ou de árvores já implantadas, por meio de vandalismo, o que, segundo Zem e Biondi (2014), pode decorrer da falta de planejamento prévio do local adequado para introduzi-las, como pouco ou nenhum envolvimento da população nas fases de plantio e manutenção das mesmas. Cidades que possuem viveiro municipal podem utilizar desta estrutura como base para uma educação ambiental eficiente. A utilização dos viveiros municipais como forma de fomentar a educação ambiental tem sido considerada como essencial.

Além da arborização urbana, os viveiros podem incentivar ações de recuperação das áreas degradadas. Inicialmente, dos $340.086,70 \mathrm{~km}^{2}$ de áreas goianas, $329.595,00 \mathrm{~km}^{2}$ eram Cerrado, mas no ano de 2008 este valor reduziu-se para 115.008 km². Crixás foi o município goiano que mais sofreu desmatamento em sua área de Cerrado entre 2002-2008 (491,00 km²), seguido de Caiapônia $\left(455,00\right.$ km²) e Nova Crixás $\left(373,00 \mathrm{~km}^{2}\right)$ (Brasil, 2009). Nenhum destes municípios citados possui viveiro municipal, de acordo com o levantamento realizado, o que pode dificultar ações de recuperação destas áreas. Não só a taxa de desmatamento deve ser levada em consideração, como fator prioritário para a conservação. Municípios como o Montividiu, Uruana, Nova Glória, Rialma, São João da Paraúna, Perolândia, Anápolis, Rio Verde, Porteirão, Maurilandia, Santa Helena de Goiás, Nerópolis, Chapadão do Céu possuem mais de 70,00\% de sua área ocupada por culturas agrícolas, chegando ao caso de Montividiu uma ocupação de 94,00\% (SANO et al., 2006). Isto pode sugerir que estes municípios podem apresentar Reservas Legais $(R L)$ compensadas em outras localidades, ou que suas propriedades, em muitos casos, não atendam à legislação vigente para a região (no mínimo 20,00\% de RL). Dessa forma, estimar a necessidade de investimentos na capacidade produtiva de mudas de espécies nativas do bioma Cerrado, para atender às demandas atuais, se faz necessário.

Em um levantamento referente à vulnerabilidade a erosão no estado de Goiás (SANO et al., 2006), foi observado que $60,0 \%$ da área do estado eram consideradas como "estável ou medianamente estável, boa a regular pra uso antrópico". Os outros $40,00 \%$ da área de Goiás eram classificados como "vulnerável ou moderadamente vulnerável" à erosão, sendo inadequada a regular para uso antrópico. A principal classe de solos do estado é o Latossolo, presente em $52,0 \%$ do estado, que de maneira geral possui elevada permeabilidade e é apto ao agronegócio, como consequência é mais explorado que os demais. Entretanto, $40,00 \%$ dos solos goianos são argissolos, nitossolos, cambissolo, neossolos litóllicos e quartzarênicos, os quais apresentam suscetibilidade à erosão com baixa aptidão agrícola (SANO et al., 2006). Municípios como que possuem em suas regiões solos susceptíveis a erosão e não possuem viveiro municipal deveriam buscar alternativas para produção de mudas visto a urgente necessidade de restauração ambiental. Sendo assim, é necessário um maior monitoramento e preparo para recuperação de áreas degradadas nestes locais, diferente de municípios que possuem em suas instalações viveiros municipais produtores de mudas. 


\section{CONCLUSÕES}

Os municípios localizados nas regiões mais centrais e com maior número de habitantes possuem viveiros administrados por prefeituras. A ausência de viveiros municipais pode comprometer a arborização urbana, recuperação de áreas degradadas e a dificuldade na obtenção de mudas para cumprimento de projetos de regularização ambiental. As parcerias das prefeituras com instituições de ensino e pesquisa, públicas ou particulares, podem incentivar novas politicas públicas voltadas para a produção de mudas no estado de Goiás.

\section{REFERÊNCIAS}

ALONSO, J. M.; LELES, P. S. DOS S.; SILVEIRA FILHO, T. B.; MESQUITA, C. A. B.; PEREIRA, M. L.; SALES JUNIOR, J. A. S. DE; ALVES, F. L.; SILVA, C. DE O. DA. Avaliação da diversidade de espécies nativas produzidas nos viveiros florestais do estado do Rio de Janeiro. Floresta, Curitiba, v. 44, n. 3, p. 369-380, 2014.

ANGeOletto, F.; SANTOS, J. W. M. C.; SANZ, J. P. R.; SILVA, F. F.; ALBERTíN, R. M. Tipologia socio-ambiental de las ciudades medias de Brasil: aportes para um desarrollo urbano sostenible. Urbe Revista Brasileira de Gestão Urbana, [s.I.], v. 8, n. 2, p. 272-287, 2016.

BIONDI, D; LEAL, L. Caracterização das plantas produzidas no horto municipal de Barreirinha Curitiba/PR, Revista da Sociedade Brasileira de Arborização Urbana, Piracicaba, v. 3, n. 2, p. 20-36, 2008.

BRASIL. Ministério do Meio Ambiente. Instituto Brasileiro do Meio Ambiente e dos Recursos Naturais Renováveis. Relatório Técnico de Monitoramento do Desmatamento no Bioma Cerrado, 2002 a 2008: Dados Revisados. Brasília: IBAMA, 2009. 71 p.

DA SILVA, O. H.; LOCASTRO, J. K.; SANCHES, S. DA. P. NETO, G. DE A.; DE ANGELIS, B. L. D.; CAXAMBÚ, M. G. Avaliação da arborização viária da cidade de São Tomé, Paraná. Ciência Florestal, Santa Maria, v. 29, n. 1, p. 371-384, 2019.

DUARTE, T. E. P. N.; ANGEOLETTO, F.; SANTOS, J. W. M. C.; DA SILVA, F. F.; BOHRER, J. F. C.; MASSAD, L. F. F. Reflexões sobre arborização urbana: desafios a serem superados para o incremento da arborização urbana no Brasil. Revista em Agronegócio e Meio Ambiente, Maringá, v. 11, n. 1, p. 327-341, 2018.

FREITAS, A. F; FREITAS, A. F; FREITAS, A. F. Caracterização dos viveiros florestais de Viçosa, Minas Gerais: Um estudo exploratório. Desenvolvimento em Questão, Viçosa, n. 22, p. 208234. 2013.

GONÇALVES, E. O; PAIVA, H. N; GONÇALVES, W; JACOVINE, L. A. G. Diagnóstico dos viveiros municipais no estado de Minas Gerais. Ciência Florestal, Santa Maria, v. 14, n. 2, p. 112. 2004. 
IBGE. Censo Demográfico 2010. Instituto Brasileiro de Geografia e Estatística. 2010. Disponível em: $\quad$ http://cidades.ibge.gov.br/xtras/perfil.php?lang=\&codmun=521190\&search=goias|jatai>. Acesso em: 07 ago. 2020.

IPEA. Secretaria de Assuntos Estratégicos da Presidência da República. Instituto de Pesquisa Econômica Aplicada. Diagnóstico da Produção de Mudas Florestais Nativas no Brasil. Brasília: IPEA, 2015. 58 p.

MARTELLI, A. Arborização urbana versus qualidade de vida no ambiente construído. Revista Científica Faculdades do Saber, Mogi Guaçu, v. 1, n. 2, p. 133-142, 2016.

MARTINS, R. L; CAILAVA, E. R; SOUZA, R. T. S. Viveiros da bacia do rio Macaé e as novas demandas para a recuperação de áreas degradadas. Boletim do Observatório ambiental Alberto Ribeiro Lamego, Campos dos Goytacazes, v. 8, n. 1, p. 83-100, 2014.

MESQUITA, C. A. Desenvolvimento e qualificação dos viveiros florestais do Espírito Santo. Espírito Santo, 2011. 17p. Programa Estadual de Ampliação da Cobertura Florestal, (Relatório Pró-viveiros).

NORTH, E. A.; JOHNSON, G. R.; BURK, T. E. Trunk flare diameter predictions as an infrastructure planning tool to reduce tree and sidewalk conflicts. Urban Forestry \& Urban Greening, [S.I.], n. 1, v. 14, p. 65-71, 2015.

PIVETTA, K. F. L; SILVA FILHO, D. F. Arborização urbana. Boletim acadêmico UNESP/FCAV/FUNEP: Jaboticabal, 2002. 69p. Disponível em: <http://www.uesb.br/flower/alunos/pdfs/arborizacao_urbana\%20Khatia.pdf> Acesso em: 30 ago. 2016.

RAMOS, L. DE F.; RIBEIRO, R. G.; LOPES, T. W. R. DOS S.; SILVA, I. M. DA.; CARDOSO, L. F. DA C. G.; MUAKAD, L. A.; SANCHEZ, S. B. Educação ambiental para alunos dos cursos Técnicos em Agroecologia e Meio Ambiente: construindo um viveiro educativo. Cadernos de Agroecologia, Dourados, v. 7, n. 2, p. 1-4, 2012.

SANO, E. E; DAMBROS, L. A; OLIVEIRA, G. C; BRITES, R. S. Padrões de cobertura de solos do estado de Goiás. In: Conservação da biodiversidade e uso sustentável em Goiás: Estratégias, prioridades e perspectivas, 2006, Goiânia: Editora, p. 192. 2006.

SANTOS, J. J; QUEIROZ, S. E. E. Diversidade de espécies nativas arbóreas produzidas em viveiros. Enciclopédia Biosfera, Goiânia, v. 7, n. 12. p. 1-7, 2011.

SANTOS, M. O.; MAIA, L. P. S. S.; OLIVEIRA, E. D.; SILVA NETO, J. C. A.; CELLA, W. Percepção ambiental sobre a arborização urbana no bairro Santa Tereza, Tefé, Amazonas, Brasil. Revista Ra'eGa, [s.I.], v. 44, p. 231-241, 2018.

SILVA, S. L. DA; MORAES, M. V. A. R. Arborização Urbana: Percepção Ambiental dos Residentes do Entorno do Viveiro de Mudas da Zona Norte, Teresina - Piauí. Espaço Aberto, Rio de Janeiro, v. 6, n. 2, p. 127-145, 2016.

SOUZA, M. G. S.; GOULART, L. R.; OLIVEIRA, E. S.; AGOSTINO, T. H.; ROCHA, K. C. G. Influência da arborização urbana no microclima de São José do Rio Preto-SP. Revista Eletrônica Engenharia Debates e Estudos, [s.I.], v. 1, n. 1, p. 1-10, 2017.

VASCONCELOS, Y. L; YOSHITAKE, M; FRANÇA, S. M; SILVA G. F. Métodos de custeio aplicáveis em viveiros florestais. Custo e @gronegócios online, Recife, v. 8, n. 2, p. 158-175. 2012. 
WALKER, C.; ARAÚJO, M. M.; MACIEL, C. G.; MARCUZZO, S. B. Viveiro florestal: evolução tecnológica e legalização. Revista Verde, Mossoró, v.6, n.5, p. 08-14, 2011.

WINTERS, G. H. M; PERRENOUD, L. A. S; MOHAMED, E. M. H. M. A arborização urbana em 295 municípios de São Paulo. In: CONGRESSO BRASILEIRO SOBRE ARBORIZAÇÃO URBANA, Vitória, 1992. Anais.... Vitória: SMMA, p.175-192. 1992.

ZEM, L. M.; BIONDI, D. Análise da percepção da população em relação ao vandalismo na arborização viária de Curitiba-PR. Revista da Sociedade Brasileira de Arborização Urbana, Curitiba, v. 9, n. 3, p. 86-107, 2014. 